\title{
Correlation of leadership and care coordinator performance among primary care physicians
}

This article was published in the following Dove Press journal: Journal of Multidisciplinary Healthcare

\section{Retno Asti Werdhani,' Astrid Widajati Sulistomo,' Herqutanto,' Ismail Wirawan, ${ }^{2}$ Ekowati Rahajeng, ${ }^{3}$ Adi Heru Sutomo, ${ }^{4}$ Muchtaruddin Mansyur ${ }^{1,5}$ \\ 'Department of Community Medicine, Faculty of Medicine, Universitas Indonesia, Jakarta, Indonesia; ${ }^{2}$ Department of Management, Faculty of Economy, Universitas Persada Indonesia, Jakarta, Indonesia; ${ }^{3}$ Researches and Development Unit, Ministry of Health Republic of Indonesia, Jakarta, Indonesia; ${ }^{4}$ Department of Family Medicine, Community, and Bioethics, Faculty of Medicine, Universitas Gadjah Mada, Yogyakarta, Indonesia; ${ }^{5}$ SEAMEO-RECFON, Universitas Indonesia, Jakarta, Indonesia}

\section{Video abstract}

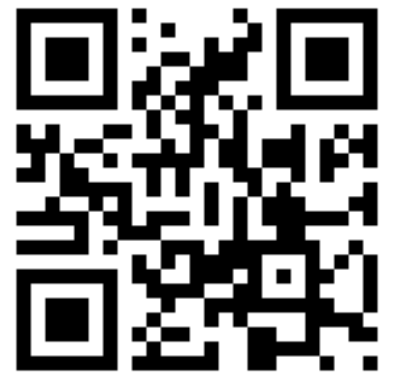

Point your SmartPhone at the code above. If you have a QR code reader the video abstract will appear. Or use: http://youtu.be/Cl_tKKjHPlk

Correspondence: Retno Asti Werdhani Department of Community Medicine, Faculty of Medicine, Universitas Indonesia, Jl. Sindang 2 no FI, Komp. Pertamina, Jati, Pulo Gadung, East Jakarta I3220, Indonesia

Tel +62811902081

Fax +62213141066

Email retno.asti@ui.ac.id
Purpose: Primary care physicians have to deal with many aspects of the patients' health problem, which needs cooperation with other health professionals or even nonhealth individuals. To achieve effective results, the primary care physicians should have leadership and coordinating skills, especially when dealing with the health challenges in Asia Pacific region. The care coordinator role of primary care physicians is important to create the bridge between population and health. This study aims to determine the correlation between care coordinator performance and leadership factors among primary care physicians.

Materials and methods: A cross-sectional study was conducted, and data collection involved a total of 84 primary care physicians who were randomly selected from a total of 44 subdistricts and worked in 40 randomly selected village government-owned primary healthcare facilities in Jakarta. Pearson's correlation, independent $t$-test, and one-way ANOVA were used to measure the correlation between care coordination and clinical leadership, transformational leadership, commitment, job satisfaction, and organizational culture, as well as the sociodemographics of the physicians and the professional practice factors. Multiple regressions were conducted to determine the most important factors influencing care coordinator performance.

Results: Respondents were mainly female (94\%) with an average age of 36 years and were mostly medical doctors without any additional postgraduate degrees $(95.2 \%)$. There was no correlation between care coordinator scores and organizational culture or commitment. There were positive and significant correlations between care coordinator scores and clinical leadership score $(r=0.66 ; P<0.001)$, transformational leadership score $(r=0.54 ; P<0.001)$, job satisfaction score $(r=0.31 ; P=0.004)$, physician's age ( $r=0.34 ; P=0.002)$, length of time since graduation ( $r=0.30 ; P=0.005)$, duration of employment at their health center $(r=0.33 ; P=0.003)$, training in family medicine $(P=0.04)$, and employment status $(P=0.005)$. The most important factors in care coordinator performance were clinical leadership $(r=0.53 ; P<0.001)$ and transformational leadership ( $r=0.23 ; P=0.03$ ), with the total $R^{2}$ being 0.47 .

Conclusion: Clinical leadership and transformational leadership were the most important factors for care coordinator performance. Therefore, the leadership skills of primary care physicians are important to be considered as a certain competency in practice to manage various resources and coordinate with related healthcare providers for controlling patients' illness as well as dealing with the challenges and managing the overall health.

Keywords: care coordinator, clinical, leadership, medicine, transformational

\section{Introduction}

Determinants of health will influence the health system through a population's health, thus it will need the crucial role of healthcare professionals. ${ }^{1}$ To provide excellent, 
comprehensive, and continuous service, primary care physicians are expected to be gatekeepers, to work together and coordinate with various parties for the benefit of their patients. ${ }^{2,3}$ Physicians and other health providers need to know the patient's background and family to communicate and coordinate with care givers and other health services. ${ }^{4}$ Bodenheimer et $\mathrm{al}^{2}$ stated that primary care physicians should also be coordinators, aiming to integrate interlevel health services for the sake of strengthening the quality of services, not just act as gatekeepers. McWhinney and Freeman ${ }^{5}$ reported that primary care physicians should act as care managers and providers, as well as associate with other health and social services. In addition, primary care physicians also act as patient advisors. Starfield et $\mathrm{al}^{6}$ claimed that primary care consists of comprehensive, longitudinal, and coordinated services in the context of family and community. There is a relationship between the coordinated management of health problems with improving the quality of patient's health as well as decreasing referral rates and home care between $8 \%$ and $46 \%$. Conducting care coordinators will improve the empowerment of patients and their families in handling the disease. ${ }^{7}$ Therefore, the function of primary care physicians as care coordinators is a core service in primary health care. ${ }^{8}$

Leadership skills are part of the physician's development program in primary healthcare services. ${ }^{9}$ The Indonesian Ministry of Health's primary healthcare strategic roadmap confirms the need for competent and culturally oriented human resource performance to achieve national health goals, which is also in line with the WHO's goals for primary care more than ever. ${ }^{10-12}$ Therefore, human resource's skills of leadership are vital considerations in routine healthcare services, including case management.

The function of primary care physicians as care coordinators and their interactions with patients cannot be separated from their leadership ability, although the physician is not formally the head of the healthcare center. ${ }^{13}$ Several factors contribute to leadership, such as organizational culture, commitment, and job satisfaction. ${ }^{14}$ Moreover, transformational leadership is required in the medical field. ${ }^{15}$ The five star doctors of WHO act as community leaders and managers and are assets to health care reformation. ${ }^{16}$

This study intends to determine the association of leadership and other professional factors toward care coordinator performance as well as the most dominant contributing factors toward care coordinator performance. The results of this study can be used to strengthen the quality of human resources in health care since primary care physicians are considered as one of the leaders of health system, ${ }^{1}$ especially when dealing with the health challenges in the Asia Pacific region, which involve many factors such as environment, communicable and non-communicable diseases, as well as reproductive care, child care, adolescent care, and care for older person. ${ }^{17}$ The results of this research can also be used as a benchmark, especially for urban health as these services will become the health trend of the 21 st century. ${ }^{18}$

\section{Materials and methods}

This research has received ethical approval from the Research Ethics Committee of Faculty of Medicine, Universitas Indonesia (number 265/UN2. F1/ETIK/2015). Care coordinator sampling instruments with valid items $(r=0.45-0.72)$ and reliable instrument set (Cronbach's alpha 0.94) were used based on previous validation results. ${ }^{19}$ Leadership instruments were also used, such as organizational culture (Cameron and Quinn), ${ }^{20}$ commitment (Allen-Meyer and Stephen Jaros), ${ }^{21}$ clinical leadership (NHS England), ${ }^{22}$ transformational leadership (Bass and Avolio), ${ }^{23}$ and job satisfaction (Minnesota). ${ }^{24}$ All of the above items of the leadership instruments have been tested prior to the research in 30 primary care physicians and were found to have good interitems correlation (0.30-0.89) and were reliable instruments (Cronbach's alpha 0.76-0.92).

A cross-sectional study was conducted, and data collection involved a total of 84 primary care physicians who were randomly selected from a total of 44 subdistricts and who worked in 40 randomly selected village government-owned primary healthcare facilities in Jakarta. All selected primary care physicians were explained about the purpose of the study and they signed a consent letter prior to data collection. Variables that were collected from the samples were care coordinators' score, leadership factors, sociodemographic factors as well as professional practice experience, and association among all the above variables to determine the most dominant variables toward care coordinator performance. Scores of each physician's performance as a care coordinator were collected from the employers, co-workers, and selfassessment by a multisource feedback method.

Descriptive data were presented in averages and SD or percentages. Pearson's correlation, independent $t$-test, and one-way ANOVA tests were used to find the relationship between various independent variables toward care coordinator scores. Multivariate analysis of multiple linear regressions was used to find the strongest determinant variable of care coordinator performance. ${ }^{25}$ SPSS 20 analysis software was used for data processing. From the results of the analysis, a framework was developed to understand the relationship between leadership factors and care coordinator performance. 


\section{Results}

\section{Sociodemographic factors and professional practice}

Physicians who worked at the government primary healthcare centers in Jakarta were almost all female (94\%), with an average age of 36 years, and most of them were medical doctors (MD) without any additional postgraduate degrees (95.2\%). Respondents had been physicians for an average of 11 years and practitioners at their particular healthcare center for 8 years. Most of them were government employees (67.5\%) and have never received training in family medicine $(61.4 \%)$.

\section{Leadership factors}

The clinical leadership score was 25.67 (out of 32). The transformational leadership score was 8.76 (out of 12). Sixtyfour percent of the physicians had high transformational leadership ability (score above 8 ). The job satisfaction score was 79.72 (out of 100). The commitment score was 62.97 (out of 80).

In comparison between current conditions and expectations, clan and adhocracy/creative culture in primary healthcare institutions were expected to be higher (score increase from 26.67 to 28.92 and from 21.77 to 24.51 ). However, hierarchical and competitive/market culture was expected to decline (decrease in score from 26.15 to 23.58 and from 25.39 to 22.97$)$.

\section{Care coordinator scores}

The care coordinator scores from employers, co-workers, and self-assessment provided almost the same results $(7.65 \pm 1.03$, $7.33 \pm 1.06$, and $7.46 \pm 1.11$, respectively) and there was no statistically significant difference $(P=0.15)$. Table 1 shows the care coordinator scores derived from the average calculation from self assessment, superiors, as well as colleagues using previously validated instruments. ${ }^{19}$ Among the 11 domains of care coordination, giving medication and preventive information to patients achieved the highest score. However, the domain of follow-up care planning and self-awareness planning still needs to be strengthened as it has the lowest score among the domains.

\section{Correlation between leadership and other factors in care coordination \\ Bivariate analysis}

Tables $2-3$ show that there was a positive and significant correlation between the care coordinator score and the physician age ( $r=0.34 ; P=0.002)$, time since graduation
Table I Care coordinator scores

\begin{tabular}{|c|c|}
\hline Domain & Average $\pm S D$ (out of 9) \\
\hline Patient-centered care & $7.23 \pm 1.55$ \\
\hline Biopsychosociocultural & $7.48 \pm 1.47$ \\
\hline Functional and behavioral & $7.53 \pm 1.38$ \\
\hline Organizational abilities & $7.20 \pm 1.55$ \\
\hline Teamwork abilities & $7.18 \pm 1.62$ \\
\hline Empathy and accountability & $8.00 \pm 1.26$ \\
\hline Patient medication information & $8.19 \pm 1.22$ \\
\hline Patient prevention information & $8.11 \pm 1.28$ \\
\hline Follow-up care plan & $6.99 \pm 1.70$ \\
\hline Medical information documentation & $7.59 \pm 1.40$ \\
\hline Self-awareness and self-development & $6.79 \pm 1.66$ \\
\hline Total score & $7.48 \pm 1.06$ \\
\hline
\end{tabular}

Table 2 Correlation matrix of dependent and independent variables

\begin{tabular}{|l|l|l|}
\hline Variables & \multicolumn{2}{|l|}{$\begin{array}{l}\text { Care coordinator } \\
\text { score }\end{array}$} \\
\cline { 2 - 3 } & $\boldsymbol{r}$ & P-value* \\
\hline Clinical leadership & 0.66 & $<0.001$ \\
Transformational leadership & 0.54 & $<0.001$ \\
Job satisfaction & 0.31 & 0.004 \\
Physician's age & 0.34 & 0.002 \\
Length of time from graduation & 0.30 & 0.005 \\
Duration of employment & 0.33 & 0.003 \\
\hline
\end{tabular}

Note: *Pearson's correlation.

Table 3 Relationship between family medicine training and type of employment towards mean care coordinator score

\begin{tabular}{|l|l|l|}
\hline Variables & $\begin{array}{l}\text { Mean care } \\
\text { coordinator } \\
\text { score }\end{array}$ & P-value* \\
\hline With family medicine training & 7.76 & $0.04^{* *}$ \\
Without family medicine training & 7.27 & $0.005^{* * *}$ \\
Government employee official & 7.69 & \\
Government employee candidate & 6.50 & \\
Contract & 7.20 & \\
\hline
\end{tabular}

Note: **Independent $t$-test; ***one-way ANOVA.

Table 4 Factors contributing to care coordinator scores

\begin{tabular}{|l|l|}
\hline Variables & $\boldsymbol{R}^{\mathbf{2}}$ \\
\hline Organizational culture & 0.01 \\
Family medicine training & 0.03 \\
Time since graduation & 0.08 \\
Physician age & 0.10 \\
Length of employment & 0.09 \\
Employment status & 0.09 \\
Job satisfaction & 0.09 \\
Transformational leadership & 0.30 \\
Clinical leadership & 0.44 \\
\hline
\end{tabular}


( $r=0.30 ; P=0.005)$, duration of work as a practitioner $(r=0.33$; $P=0.003)$, clinical leadership score $(r=0.66 ; P<0.001)$, transformational leadership score $(r=0.54 ; P<0.001)$, and job satisfaction score $(r=0.31 ; P=0.004)$. The care coordinator score of those who received training in family medicine was higher (7.76) than those who had not received family medicine training (7.27) and this difference was statistically significant $(P=0.04)$. The care coordinator score of physicians who had government employee status was higher (7.69) than that of those who had other employment status (6.50 and 7.20) and this difference was statistically significant $(P=0.005)$. There was no correlation between care coordinator scores with organizational culture and commitment scores.

\section{Multivariate analysis}

Table 4 illustrates the role of various leadership factors as well as sociodemographic and professional factors in care coordinator scores, described as $R^{2}$. The contribution of clinical and transformational leadership to care coordination was $44 \%$ and $30 \%$, respectively, whereas other factors contributed $<10 \%$. Total $R^{2}$ of clinical leadership and transformational leadership for care coordination was 0.47 . This means the clinical leadership and transformational leadership scores explain $47 \%$ variation of care coordination performance (Table 5).

Based on the results of the role of leadership factors to care coordinator performance, a framework scheme was created to show the relationship as described in Figure 1.

\section{Discussion}

\section{Correlation between sociodemographic and professional factors in care coordination}

This study showed that the majority of primary care physicians in Jakarta were female (94\%). These results were in accordance with the International Labor Organization employment data, which reported that those in professional occupations, including health workers, were mostly female $(57.2 \%) .{ }^{26}$ Metcalfe and Franks ${ }^{27}$ argued that whereas male physicians have good communication skills, female physi-

Table 5 Multivariate analysis of clinical and transformational leadership to care coordinator scores

\begin{tabular}{|l|l|l|l|}
\hline \multirow{2}{*}{ Variables } & \multicolumn{3}{|c|}{ Care coordinator score } \\
\cline { 2 - 4 } & $\boldsymbol{r}$ & P-value & Beta \\
\hline Clinical leadership & 0.53 & $<0.001$ & $0.15 \mathrm{I}$ \\
\hline Transformational leadership & 0.23 & 0.030 & 0.187 \\
\hline Constant & 1.94 & & \\
\hline
\end{tabular}

Note: $R^{2}=0.47$; significance $=0.005$. cians are better at delivering bad news, using patient-centered approaches, making empathic statements, providing emotional support, and engaging in psychological discussions, all of which affect the improvement of health outcomes. This could result in the high value of empathy in the care coordinator scores in this study, as the majority of participating physicians were female.

This study also found a positive and significant correlation between ages and care coordinator scores, with higher ages receiving higher scores. This can be explained by the increase in experience, training, and confidence to perform their roles. There was a positive and significant correlation between the length of time since a physician's graduation and the length of time working at their healthcare center with the care coordinator score. This means that the longer the graduated period and time working at a health center, the higher the care coordinator score. This can be explained by the continuous experience and exposure to the work culture of the health center as part of the learning process, which can also increase confidence in performing their function as a care coordinator. It takes time to become a government employee, which comes with age and experience gained in the healthcare center. It is a long process, taking a minimum of 3 years to go from internship employment to government employee. This makes the care coordinator scores of physicians with government employee status higher than those of other employment statuses.

Care coordinator scores were significantly higher in the group of physicians who had training in family medicine. Care coordinator is a role of family/primary care physicians and is one of the subjects taught during family medicine training. For example, in training, participants are asked to have a case discussion in groups regarding the need for collaboration with other healthcare workers or relevant agencies for consultations or referrals when necessary. A specialist case-related physician is invited as a second resource person; so, all participants see both sides of case management: primary care services and secondary care services as well as other health provider responsibilities and roles. ${ }^{28}$

\section{Correlation between leadership and care coordination}

The care coordination domains with the highest scores were provision of patient medication information, prevention information, and empathy toward the patient. This is in accordance with the function of primary care physicians as providers of patient-centered health promotion, preventive, curative, and rehabilitative activities. However, follow-up care and selfawareness planning domains still need to be strengthened, as 


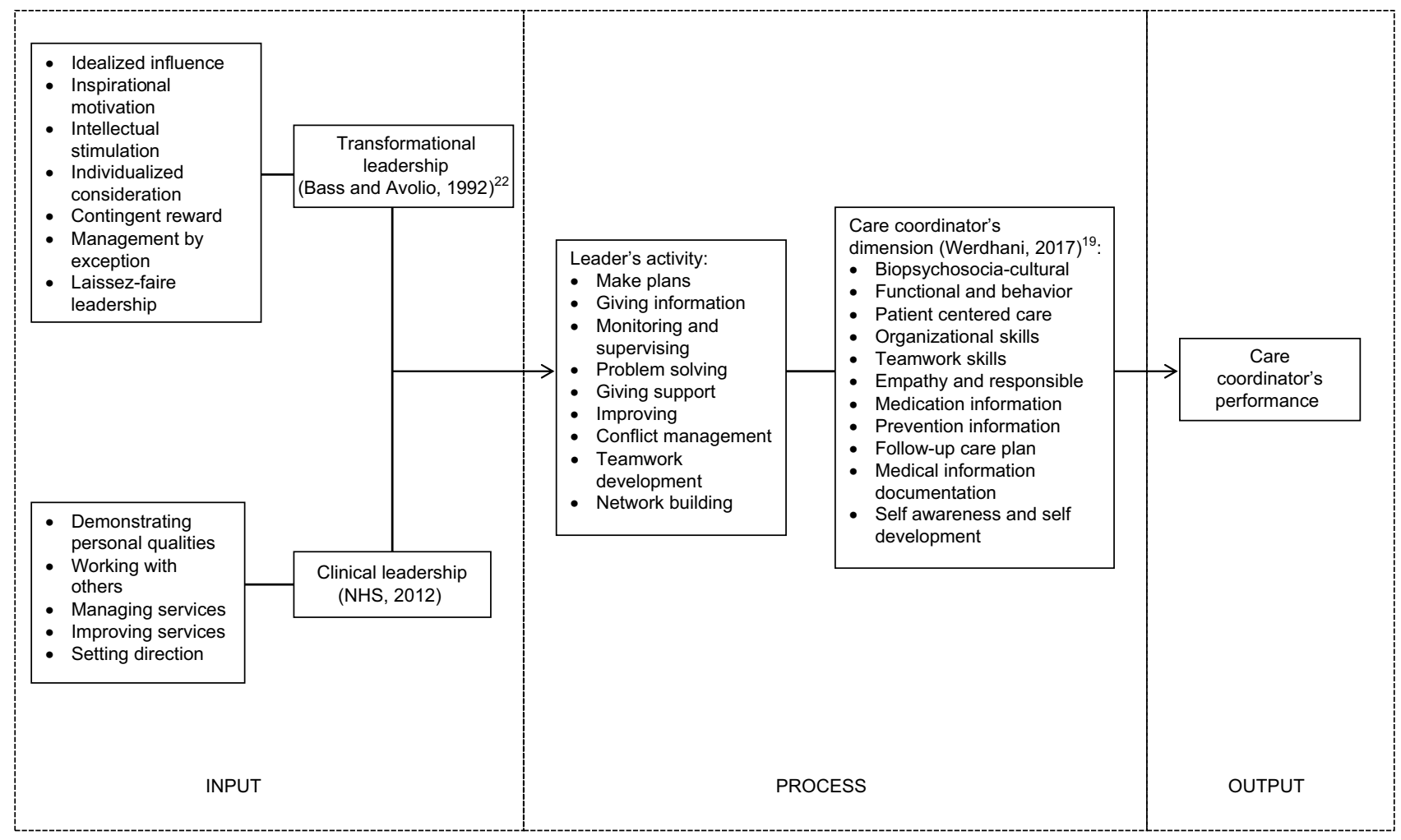

Figure I Correlation of leadership factors and care coordinator performance.

they had the lowest scores. Most of them were MD without any additional postgraduate degrees (specialist/master). In Indonesia, after the internship program, graduated MD from the School of Medicine will directly practice in primary care (at least 1 year) to fill the gap of health provider in rural/ remote area. After that, they can continue practice in primary care or continue as a formal secondary care specialist or go for a master degree. This is somewhat different from other Southeast Asian countries such as Malaysia, Singapore, and Philippines, where a physician who wants to practice in primary care needs to take a formal and structured postgraduate/specialist degree. The improvement of knowledge and skills for a primary care physician in Indonesia was achieved by continuing professional development course training (nonformal education) provided by the professional organization, including family medicine training. The number of respondents continuing their professional development as required for competency recertification and license to practice was not known in this study.

The percentage of primary care physicians who obtained a transformational leadership score above 8 (high category) was $64 \%$. This high score in transformational leadership may have been due to the high proportion of female physicians. In a research conducted by Mandell and Pherwani, ${ }^{29}$ there was a significant relationship between emotional intelligence and transformational leadership, and emotional intelligence scores were higher in females than males. In the same study, the transformational leadership score in females was higher than males, but it was not statistically significant. ${ }^{29}$

The high score of clan and hierarchal culture in primary care shows the existence of structural and familial cultures. It is common for government organizations to require a bureaucratic approach to streamline the implementation and control of large numbers of people. ${ }^{15}$ The nature of the entrepreneurial (adhocracy and market) culture was less visible than the other two cultures (hierarchy and clan). This is in accordance with the nature of government-owned primary care, which has a bureaucratic government and nonprofit culture without competition. On the other hand, healthcare services are growing rapidly and require innovation and renewal to keep up-to-date. The participants reflected that adhocracy culture is becoming more visible, but not reducing the clan culture that has been there before; however, the structural and hierarchal culture needs to be reduced.

This study found that clinical leadership and transformational leadership were the two dominant factors related to primary care physicians' performance as care coordinators. When examined, there was an alignment of all care coordina- 
tor dimensions of the used instruments ${ }^{19}$ with these three variables (clinical leadership, transformational leadership, and care coordination). The domains of biopsychosocialcultural, behavioral and functional aspects, patient-centered, empathy and accountability aspects, and medication and preventive information in the instrument of care coordination used in this study are aligned with the transformational leadership dimension that describes the leadership behaviors and responsibilities of a physician as an individual to the patient. ${ }^{23} \mathrm{On}$ the other hand, the domains of organizational ability, teamwork ability, follow-up planning, documentation of medical information, as well as self-awareness and self-improvement are in harmony with the clinical leadership dimension that describes the leadership behaviors and accountability of a physician as part of the organization of healthcare facilities. ${ }^{22}$

This is in accordance with the concept of clinical leadership as organizing, inspiring, and promoting values using clinical experience and skills to ensure patient needs are aligned with the service and goals of the healthcare organization. ${ }^{16}$ Clinical support at the micro-level is very important to improve the quality of health services. The role of primary care physicians as practitioners, colleagues, and leaders is necessary to align patient needs with service policy. This role can be reflected in their performance as a care coordinator during interactions with patients, especially in the management of diseases that require long-term care and the collaboration of various parties.

Although statistically significant, there were no large differences in care coordinator scores between physicians who received training in family medicine compared with those who had not. Thus, it is necessary to increase the number of primary care practitioners who receive training in family medicine to obtain better care coordinator scores. The materials given during training should not only include clinical medicine but also case management simulations that show elements of collaboration among healthcare providers, including referrals, to indicate the presence of clinical leadership in case management.

The care coordinator scores in primary care in the Jakarta area are not necessarily the same as the scores at a primary care outside Jakarta or at a private clinic because the organizational culture and environment may differ. The organizational culture, local culture of the region, policies, geographical conditions, and available local resources will affect performance. ${ }^{30}$ The results of this study are expected to support the Jakarta provincial government as well as other regional governments and countries to develop innovations, particularly to increase the capacity of healthcare providers while continuing to strengthen the systems and infrastructure of service facilities.
To fulfill the needs of primary care physicians as care coordinators, leadership skills are necessary for physicians to "lead" the patient in his or her health (reflected in transformational leadership) and to be a member of the health system (reflected in clinical leadership), so that healthcare organizations can reform for the benefit of their patients. Both show the physician's role in the doctor-patient interaction (micro-level) as well as the connection between the microlevels and the meso-levels (head of healthcare facilities), to ensure that healthcare organization standards are aligned with patient and professional needs (bottom up). However, without leadership support from meso- and macro-level health systems (top down) as well as external organizational factors, healthcare reform will not occur, no matter how good the service is at the micro-level. ${ }^{13}$

The results of this study prove that primary care physicians are expected to have clinical and transformational leadership competencies to support their performance as care coordinators, especially when care requires long-term management and monitoring through a team-based approach.

Swanwick and Mckimm ${ }^{31}$ reported that leadership development and evaluation as well as feedback should be available at every level of the education and training of healthcare professionals. This study showed that the primary care physician's performance as a care coordinator was dominated by the practitioner's leadership skills. Therefore, strengthening and training the leadership skills of primary care physicians is needed in the future, requiring physicians to lead case management teams. The development of physicians as practitioners, associates, and leaders requires organizational reform and individual change $^{32}$ to enable primary care physicians to become agents of change, with the clinical and transformational leadership to support their function as care coordinators.

In further research, the physician's emotional intelligence, as well as knowledge about clinical protocol/clinical pathway and job descriptions can be included,

\section{Recommendation}

The leadership skill of primary care physicians is important to manage various resources and coordinate with related healthcare providers to control patient illness as well as manage the overall health. Leadership skills can be learned with exposure and experiences to sharpen group collaboration, organizational and communication abilities in managing patient health problems, especially those requiring longterm management and multiple modes of interdisciplinary interventions. This will need primary care physician as part of the professional health team and a hub of coordination to manage and monitor patient's care as well as for the continu- 
ity of care. This leadership skill will be beneficial to improve patient's quality of life with a multidisciplinary approach through patient and family empowerment.

This research gives an impact of including the leadership material in medical and health undergraduate curriculum as a foundation and advanced course in primary care/family medicine's postgraduate training degree as well as other healthcare professional training in other countries. Therefore, the development of leadership modules for postgraduate primary care physicians and other health care professional training as teamwork is needed to improve clinical and transformational leadership competencies to support the primary care physician's performance as a care coordinator.

Further research will need to be conducted to determine how much the role of a care coordinator, clinical leadership, and transformational leadership, among other factors, influence patient disease control using a longitudinal design to see the long-term impact.

\section{Conclusion}

There were positive and significant correlations between physician age, length of time since graduation, length of employment, clinical leadership score, transformational leadership score, and job satisfaction score toward care coordinator scores. Care coordinator scores in physicians who had received training in family medicine and had government employment status were significantly higher. Among all factors that correlated with care coordinator scores, clinical leadership and transformational leadership were the most dominant factors for care coordinator performance $\left(R^{2} 0.47\right)$.

\section{Acknowledgments}

The authors would like to thank the Provincial Health Office (PHO) and The District Health Offict (DHO) Jakarta for giving permission to collect data. This publication was supported by Directorate of Research and Community Engagement Universitas Indonesia Number: 5282/UN2.R3.1/HKP 05.00/2018.

\section{Disclosure}

The authors report no conflicts of interest in this work.

\section{References}

1. World Health Organization. Training Modules for Teaching of Public Health in Medical School in South-East Asia Region. New Delhi: World Health Organization; 2015.

2. Bodenheimer T, Lo B, Casalino L. Primary care physicians should be coordinators, not gatekeepers. JAMA. 1999;281(21):2045-2049.

3. Stille CJ, Jerant A, Bell D, Meltzer D, Elmore JG. Coordinating care across diseases, settings, and clinicians: a key role for the generalist in practice. Ann Intern Med. 2005;142(8):700-708.
4. Rothman AA, Wagner EH. Chronic illness management: what is the role of primary care? Ann Intern Med. 2003;138(3):256-261.

5. McWhinney IR, Freeman T. Principles of family medicine. Textbook of Family Medicine. 3rd ed. Oxford: Oxford University Press; 2009: 13-29.

6. Starfield B, Shi L, Macinko J. Contribution of primary care to health systems and health. Milbank Q. 2005;83(3):457-502.

7. Meyers D, Peikes D, Genevro J. The roles of patient-centered medical homes and accountable care organizations in coordinating patient. U.S. Department of Health and Human Services. Agency for Healthcare Research and Quality. 2010.

8. Starfield B. Public health and primary care: a framework for proposed linkages. Am J Public Health. 1996;86(10):1365-1369.

9. Agency of Development and Empowerment of Health Human Resources in Ministry of Health. Curriculum of Training of Trainers for Primary Care Physicians' Lecturer. 2014.

10. Ministry of Health Republic of Indonesia. Healthcare Strategic Plan Year 2015-2019. 2015.

11. Taher A. Policy and Strategy for Improving Health Services in DKI Jakarta (presentation slide). 2014.

12. DKI Jakarta Provincial Health Office. Strategic Plan of DKI Jakarta Provincial Health Office Year 2013-2017. Jakarta; 2013.

13. Werdhani RA. Leadership in doctor-patient relationship: implementation on patient's case management in primary care. Med J Indones. 2017;26(2):158-166.

14. Wirawan. Leadership: Theory, Psychology, Organizational Behavior, Application and Research. 1st ed. Jakarta: Rajagrafindo Persada; 2013.

15. Edmonstone J. Clinical Leadership Development. Edmonstone J, editor. 1st ed. Chicester: Kingsham Press; 2005.

16. Boelen C. The Five-Star Doctor: An Asset to Healthcare Reform? Geneva: WHO; 2000.

17. World Health Organization Regional Offices for South-East Asia and the Western Pacific. Health in Asia and the Pacific. Manila; 2008.

18. World Health Organization. Urban Health. Geneva: WHO; 2010.

19. Werdhani RA, Sulistomo A, Mansyur M, et al. Development of a care coordinator performance measurement tool for Indonesian family physicians. Eur J Pers Cent Healthc. 2017;5(3):317-323.

20. Suderman J. Using the organizational cultural assessment (OCAI) as a tool for new team development. J Pract Consult. 2012;4(1):52-58.

21. Jaros S. Meyer and Allen model of organizational commitment: measurement issues. J Organ Behav. 2007; VI (4):7-25.

22. National Health System Leadership Academy. Clinical Leadership Competency Framework. 2012.

23. Bass BM, Avolio BJ. MLQ Multifactor Leadership Questionnaire. Redwood City: Mind Garden; 2000.

24. Vocational Psychology Research. Minnesota Satisfaction Questionnaire. Minneapolis: University of Minnesota; 1977.

25. Stockburger DW. Multiple regressions with categorical predictor variables [Internet]. Available from: http://www.psychstat.missouristate. edu/multibook $/ \mathrm{mlt} 08 . \mathrm{htm}$.

26. International Labor Organization. Tren Ketenagakerjaan dan Sosial di Indonesia 2014-2015. Jakarta; 2015.

27. Metcalfe B, Franks M. Gender and leadership. In: Swanwick T, McKimm J, editors. ABC of Clinical Leadership. 1st ed. Oxford: Blackwell Publishing; 2011:60-64.

28. Community Medicine Department Faculty of Medicine Universitas Indonesia. Program Module of Postgraduate Family Medicine Diploma. 2nd ed. Jakarta: Faculty of Medicine Universitas Indonesia; 2013.

29. Mandell B, Pherwani S. Relationship between emotional intelligence and transformational leadership style: a gender comparison. $J$ Bus Psychol. 2003;17(3):387-404.

30. Wirawan. Evaluasi Kinerja Sumber Daya Manusia: Teori, Aplikasi, Penelitian. 2009.

31. Swanwick T, Mckimm J. What is clinical leadership....and why is it important? Clin Teach. 2011;8(1):22-26.

32. Swanwick T, McKimm J. ABC of Clinical Leadership. West Sussex: Wiley-Blackwell; 2011. 
The Journal of Multidisciplinary Healthcare is an international, peerreviewed open-access journal that aims to represent and publish research in healthcare areas delivered by practitioners of different disciplines. This includes studies and reviews conducted by multidisciplinary teams as well as research which evaluates the results or conduct of such teams or health care processes in general. The journal covers a very wide range of areas and welcomes submissions from practitioners at all levels, from all over the world. The manuscript management system is completely online and includes a very quick and fair peer-review system. Visit http://www.dovepress.com/ testimonials.php to read real quotes from published authors.

Submit your manuscript here: https://www.dovepress.com/journal-of-multidisciplinary-healthcare-journal 